\title{
Experimental study on single factor effect of divergent ultrasonic degradation of methylene blue in water
}

\author{
Yong-guang $\mathrm{Bi}^{1,2}$, Xin-ting Zhang ${ }^{2}$, Shao-qi Zhou ${ }^{1,3^{*}}$ \\ ${ }^{1}$ School of Environment and Energy, South China University of Technology, Guangzhou 510006, Guangdong, China \\ ${ }^{2}$ School of Pharmacy, Guangdong Pharmaceutical University, Guangzhou 510006, Guangdong, China \\ ${ }^{3}$ Guizhou Academy of Sciences, Guiyang 550001, Guizhou, China
}

\begin{abstract}
The study of divergent ultrasonic degradation of methylene blue in water was carried out by exploring the ultrasonic intensity of the methylene blue, the initial concentration and the degradation rate of the solution $\mathrm{pH}$. The test results show that the degradation rate of methylene blue decreases with the increase of ultrasonic power. The initial concentration of methylene blue solution is in the range of $0.00-10.00 \mathrm{mg} / \mathrm{L}$. The degradation rate of methylene blue increases as the concentration of the solution increases. when the concentration is greater than $10.00 \mathrm{mg} / \mathrm{L}$, the concentration increases, and the ultrasonic degradation rate decreases. When the $\mathrm{pH}$ value is higher, the degradation rate of the methylene blue solution increases with the increase of $\mathrm{pH}$, and the degradation rate reaches a maximum of $77.89 \%$. The region where the ultrasonic degradation of methylene blue occurs is mainly at the junction of gas-liquid two phases, and is degraded by forming hydrogen peroxide in the cavitation bubbles and decomposing into various highly active radicals. Ultrasound has the advantages of fast, low energy consumption and environmental friendliness.
\end{abstract}

Since the 21 st century, China's industrialization has been continuously strengthened, and industries such as fine chemicals, pharmaceuticals, printing and dyeing have developed rapidly. However, a large amount of organic polluted wastewater has been produced. Among them, organic dye wastewater accounts for a large proportion ${ }^{[1]}$. China's printing and dyeing wastewater discharges approximately $4.0 \times 106$ tons per day. These wastewaters contain many polar groups such as $-\mathrm{SO} 3 \mathrm{Na}$, $-\mathrm{NH} 2$, and chromogenic groups such as $-\mathrm{N}=\mathrm{N}-,-\mathrm{N}=\mathrm{O}$. It has toxic pollutants which are difficult to be degraded biologically containing such groups as phthalic acid, nitrobenzene, aniline, etc., which are also benzene ring, azo, amine group, etc., and are also carcinogenic substances present in wastewater. At present, the proportion of printing and dyeing wastewater to water environment pollution is becoming more serious, and the treatment of printing and dyeing wastewater is more difficult ${ }^{[2,3]}$.

Methylene blue $(\mathrm{M}=373.9$, molecular formula $\mathrm{C}_{16} \mathrm{H}_{18} \mathrm{CIN}_{3} \mathrm{~S} \bullet 3 \mathrm{H}_{2} \mathrm{O}$ ). It is a trihydrate compound with a slightly dark green bronze luster crystal, soluble in water and ethanol, and insoluble in ethers ${ }^{[4]}$. Methylene blue is more stable at room temperature, while methylene blue solution is generally toxic and alkaline. Methylene blue is not only a blue-based basic dye reagent, but also a frequently used redox indicator. It is used biologically to judge the dyeing of certain reagents and certain bacteria. It is also used in cotton, wool and other cotton. In the dyeing of fibers, the untreated methylene blue solution can seriously pollute the environment of natural waters $^{[5,6]}$.

This experiment explores the influencing factors of divergent ultrasonic degradation of methylene blue in water, in order to maximize the degradation rate, making it more economical and efficient in practical applications.

\section{Experimental method}

\subsection{Drawing of standard curve}

Determine the scanning wavelength: Prepare $\mathrm{C}=3.0 \mathrm{mg} / \mathrm{L}$ methylene blue solution, and put it into the UV-5500PC $\mathrm{UV}$-visible spectrophotometer for spectral scanning. The scanning result shows that the absorption peak is at $664 \mathrm{~nm}$, so $664 \mathrm{~nm}$ is used as the specified scanning wavelength.

Preparation of standard solution: Pipette $5.00 \mathrm{~mL}$, $6.00 \mathrm{~mL}, 7.00 \mathrm{~mL}, 8.00 \mathrm{~mL}, 9.00 \mathrm{~mL}, 10.00 \mathrm{~mL}, 11.00 \mathrm{~mL}$, $12.50 \mathrm{~mL}, 15.00 \mathrm{~mL}$ of methylene blue mother liquor in 9 gauges to avoid light. Volumetric flask, add water to the $50 \mathrm{~mL}$ mark. The cuvette thickness was $2.0 \mathrm{~cm}$, the scanning wavelength was $664 \mathrm{~nm}$ measured in the previous part of the experiment, and the reference solution was selected as deionized water, and the absorbance (A) was measured. Taking the measured absorbance $\mathrm{A}$ as the ordinate, the concentration $\mathrm{C}(\mathrm{mg} / \mathrm{L})$ of the methylene blue solution is plotted on the abscissa. 


\subsection{Single factor test of trough ultrasonic degradation of methylene blue in water}

The methylene blue powder was accurately weighed and solventized with deionized water to prepare a certain concentration of methylene blue reaction solution. We determined the reaction time and reaction temperature by using the control variable method, ultrasonic power, initial concentration and $\mathrm{pH}$ value. We also studied the effect of each factor on the degradation rate of methylene blue.

The solution after precise measurement was placed in a brown $50 \mathrm{~mL}$ volumetric flask, and deionized water was added to prepare a solution whose absorbance fell in the regression equation. The absorbance value was measured at a UV absorption wavelength of $664 \mathrm{~nm}$, and substituted into a standard curve to obtain a reaction. The concentration of methylene blue in the liquid is then calculated according to the formula.

Degradation rate $(\%)=($ methylene blue concentration before degradation - methylene blue concentration after degradation) / methylene blue concentration before degradation $\mathrm{x} 100 \%$

\section{Results and analysis}

\subsection{Drawing of standard curve}

Taking the measured absorbance $\mathrm{A}$ as the ordinate and the concentration $\mathrm{C}(\mathrm{mg} / \mathrm{L})$ of the methylene blue solution as the abscissa, the regression curve is drawn, and the regression equation is obtained: $\mathrm{A}=0.271 \mathrm{C}-0.0171$, the correlation coefficient is greater than 0.99 and close to 1.00 , ie R2 $=0.9997$, the results are shown in Figure 1 below, demonstrating a good linear relationship between methylene blue concentration $\mathrm{C}$ and absorbance $\mathrm{A}$, which can be used to calculate the degradation rate of this test.

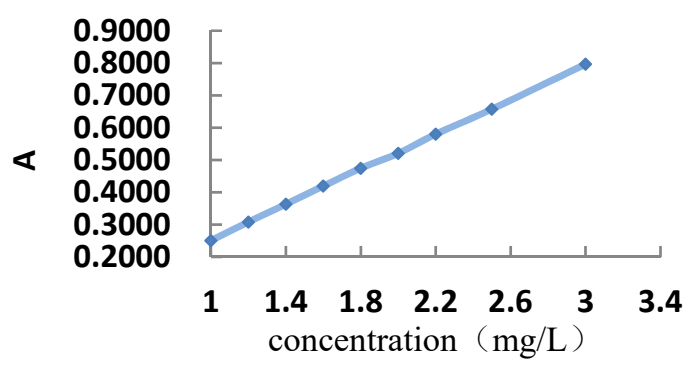

Fig.1 Standard curve of methylene blue

\subsection{Single factor test of trough ultrasonic degradation of methylene blue}

\subsubsection{Effect of trough ultrasonic power on the degradation rate of methylene blue solution}

The solution was prepared to contain $10 \mathrm{mg}$ of methylene blue per $1 \mathrm{~L}$ (measured $\mathrm{pH}=6.10$ ), $80 \mathrm{~mL}$ of each reaction was taken, and placed in a special long tube ultrasonic glass, and the outer layer was covered with a black plastic bag to protect from light. , placed in a trough ultrasound reaction. The ultrasonic frequency of the fixed reaction was $40 \mathrm{kHz}$ and the time was $20 \mathrm{~min}$. The output power of the ultrasonic wave was set to $200 \mathrm{~W}, 240 \mathrm{~W}, 280 \mathrm{~W}, 320$ $\mathrm{W}, 360 \mathrm{~W}$, respectively, and the measured degradation rate is as shown in Fig.2.

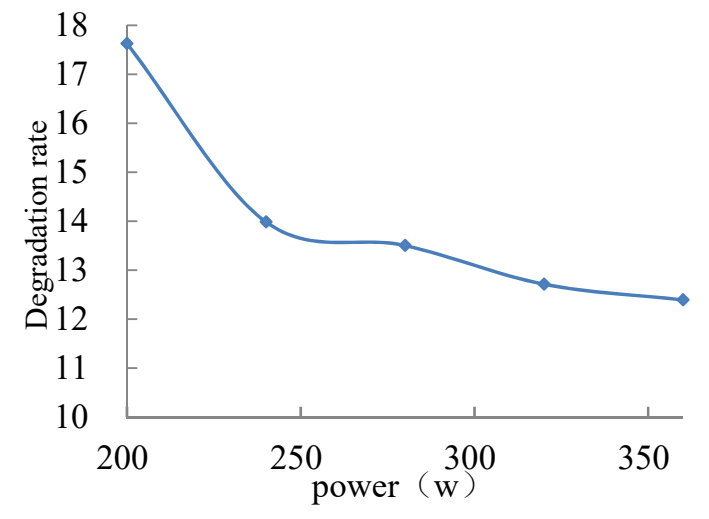

Fig. 2 Effect of power on the dissolution rate of methylene blue

It can be seen from Fig. 2 that the degradation rate is $17.63 \%$ when $\mathrm{P}=200 \mathrm{~W}, 13.99 \%$ when $\mathrm{P}=240 \mathrm{~W}$, and the degradation rate is minimized when $\mathrm{P}$ is increased to $360 \mathrm{~W}$. It is $12.39 \%$. The degradation rate of the methylene blue solution decreases as the ultrasonic power increases. This is because the minimum power of $200 \mathrm{~W}$ in the test has reached a threshold of ultrasonic power, and then the power is amplified, so that the cavitation bubbles in the ultrasonic field are formed too fast and prematurely broken, so that the methylene blue in the water body is not fully obtained. Oxidation, the degradation rate will decrease as the power increases.

\subsubsection{Effect of initial concentration of methylene blue on its degradation rate}

A methylene blue mother liquor having a concentration of $\mathrm{C}=50 \mathrm{mg} / \mathrm{L}$ was prepared with deionized water. Pipette $8.00 \mathrm{~mL}, 16.00 \mathrm{~mL}, 24.00 \mathrm{~mL}, 32.00 \mathrm{~mL}, 80.00 \mathrm{~mL}$, and prepare the same reaction solution with a concentration of $80.00 \mathrm{~mL}$ of $5.00 \mathrm{mg} / \mathrm{L}, 10.00 \mathrm{mg} / \mathrm{L}$, and $15.00 \mathrm{mg} / \mathrm{L} .20 .00$ $\mathrm{mg} / \mathrm{L}, 50.00 \mathrm{mg} / \mathrm{L}$ of methylene blue initial solution. The output power of the trough ultrasonic wave is set to $200 \mathrm{~W}$, and the reaction time is $20 \mathrm{~min}$. The degradation rate is shown in Figure 3 below.

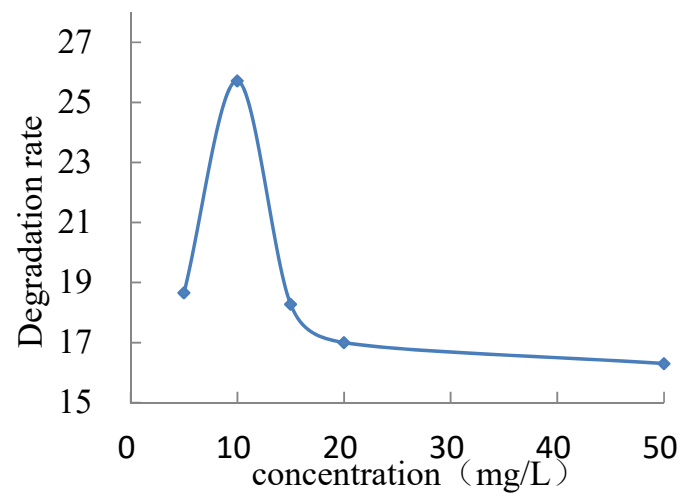


Fig. 3 Effect of initial concentration of methylene blue solution on degradation rate

It can be seen from Fig. 3 that when $C=5.00 \mathrm{mg} / \mathrm{L}$, the degradation rate is $18.66 \%$; when $\mathrm{C}=10.00 \mathrm{mg} / \mathrm{L}$, the degradation rate is $25.72 \%$, which is the maximum degradation rate. The initial concentration of methylene blue solution is in the range of $0.00-10.00 \mathrm{mg} / \mathrm{L}$. The higher the concentration, the higher the ultrasonic degradation rate; when the concentration is greater than $10.00 \mathrm{mg} / \mathrm{L}$, the concentration increases, and the ultrasonic degradation rate decreases. This is because high-activity free radicals such as hydroxyl radicals in the cavitation nucleus between $0.00-10.00 \mathrm{mg} / \mathrm{L}$ remain, so the greater the initial concentration in this interval, the higher the degradation rate. However, when the critical point exceeds $10.00 \mathrm{mg} / \mathrm{L}$, the increase of the initial concentration necessarily requires more highly active free radicals to support the reaction, but at this time, the $\mathrm{H}_{2} \mathrm{O}_{2}$ in the system has reached a constant state, and the generated free radicals such as $\mathrm{OH} \bullet$ It is constant, so the increase in the initial concentration at this time causes the degradation rate to decrease.

\subsubsection{Effect of $\mathrm{pH}$ value of methylene blue solution on its degradation rate under trough ultrasonic}

The solution was formulated into $10 \mathrm{mg}$ of methylene blue per $1 \mathrm{~L}$, and the methylene blue solution with $\mathrm{pH}=2.30,3.65,6.10,10.65$, and 12.70 was adjusted by using the diluted $\mathrm{H} 2 \mathrm{SO} 4$ solution and the dissolved $\mathrm{NaOH}$ solution, respectively, and placed in a trough ultrasonic reactor for $20 \mathrm{~min}$, ultrasonication. The output power is selected to be $200 \mathrm{~W}$. Among them, the difference between the three adjustment measurements when adjusting the $\mathrm{pH}$ does not exceed \pm 0.2 , and the last used $\mathrm{pH}$ value is the average value.

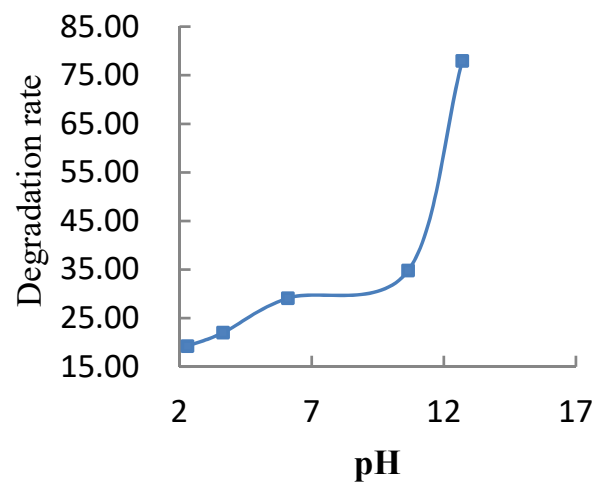

Fig. 4 Effect of $\mathrm{pH}$ value of methylene blue solution on its degradation rate

It can be seen from 4 that the degradation rate is $19.26 \%$ at $\mathrm{pH}=2.30$; the degradation rate is slowly increased to
$22.03 \%$ at $\mathrm{pH}=3.65$; the degradation rate is $29.12 \%$ at $\mathrm{pH}=6.10$; the degradation rate is $34.80 \%$ at $\mathrm{pH}=10.65$. At $\mathrm{pH}=12.70$, the degradation rate reached a maximum of $77.89 \%$. When the $\mathrm{pH}$ is higher, the degradation rate of the methylene blue solution increases with increasing $\mathrm{pH}$.

\section{Conclusion}

The test results show that the stronger the output power of the trough ultrasonic, the lower the degradation rate of the methylene blue solution. The initial concentration of methylene blue solution is in the range of $0.00-10.00$ $\mathrm{mg} / \mathrm{L}$. The higher the concentration, the higher the ultrasonic degradation rate; when the concentration is greater than $10.00 \mathrm{mg} / \mathrm{L}$, the concentration increases, and the ultrasonic degradation rate decreases. When the $\mathrm{pH}$ value is higher, the degradation rate of the methylene blue solution increases with the increase of $\mathrm{pH}$, and the degradation rate reaches a maximum of $77.89 \%$.

\section{Acknowledgement}

This work is supported by National key $R \& D$ Program of China (No.2016YFC0400707-4). and Guizhou Science and Technology Department Science and Technology Project (No.[2017]-5409-2).

\section{References}

1. MORIGUCHI N.The effect of supersonic waves on chemical phenomena(III):the effect on the concentration polarization[J].Journal of the Chemical Society Japan, 1934,55:749-750.

2. Karthik R, Muthezhilan R.Effective removal of Methylene Bluedye from water using three different low-cost adsorbents[J].Desalination and Water Treatment,2016,57(23):10626-10631.

3. Suslick K S,Iii M N,Didenko Y. Hot Spot Conditions during Multi-Bubble Cavitation[J].Sonochemistry and Sonoluminescence, 1999,524:191-204.

4. Valsaraj K T, Springer C. Removal of traces of pentachlorophenol from aqueous acidic solutions by solvent extraction and solvent sublation. Separation Science and Technology,1986,21(8):789-807.

5. Valsaraj K T. Wilson D J. Removal of refractory organics by aeration. IV. Solvent sublation of chlorinated organics and nitrophenols. Colloids and Surfaces, 1983, 8(2):203-224

6. Horng J Y, Huang S D. Removal of organic dye (Direct Blue) from synthetic wastewater by adsorptive bubble separation techniques. Environmental science\&technology, 1993, 27(6): 1169-1175. 